Article

\title{
Environmental Differences between Migratory and Resident Ungulates-Predicting Movement Strategies in Rocky Mountain Mule Deer (Odocoileus hemionus) with Remotely Sensed Plant Phenology, Snow, and Land Cover
}

\author{
Benjamin Robb ${ }^{1,2, * \mathbb{D}}$, Qiongyu Huang ${ }^{1} \mathbb{D}$, Joseph O. Sexton ${ }^{3,4}$, David Stoner ${ }^{5}$ and \\ Peter Leimgruber 1 \\ 1 Smithsonian Conservation Biology Institute, Front Royal, VA 27109, USA \\ 2 Wyoming Cooperative Fish and Wildlife Research Unit, Department of Zoology and Physiology, \\ University of Wyoming, Laramie, WY 82071, USA \\ 3 Department of Geographical Sciences, University of Maryland, College Park, MD 20740, USA \\ 4 terraPulse, Inc., Gaithersburg, MD 20878, USA \\ 5 Quinney College of Natural Resources, Utah State University, Logan, UT 84322, USA \\ * Correspondence: brobb1@uwyo.edu
}

Received: 15 July 2019; Accepted: 18 August 2019; Published: 22 August 2019

\begin{abstract}
Migration is a valuable life history strategy for many species because it enables individuals to exploit spatially and temporally variable resources. Globally, the prevalence of species' migratory behavior is decreasing as individuals forgo migration to remain resident year-round, an effect hypothesized to result from anthropogenic changes to landscape dynamics. Efforts to conserve and restore migrations require an understanding of the ecological characteristics driving the behavioral tradeoff between migration and residence. We identified migratory and resident behaviors of 42 mule deer (Odocoileus hemionus) based on GPS locations and correlated their locations to remotely sensed indicators of forage quality, land cover, snow cover, and human land use. The model classified mule deer seasonal migratory and resident niches with an overall accuracy of $97.8 \%$ and cross-validated accuracy of $81.2 \%$. The distance to development was the most important variable in discriminating in which environments these behaviors occur, with resident niche space most often closer to developed areas than migratory niches. Additionally, snow cover in December was important for discriminating summer migratory niches. This approach demonstrates the utility of niche analysis based on remotely sensed environmental datasets and provides empirical evidence of human land use impacts on large-scale wildlife migrations.
\end{abstract}

Keywords: random forest; migration; residence; partial migration; niche; GPS

\section{Introduction}

Migration, defined as repeated long-distance movements between distinct ranges, is a behavioral strategy adapted to the spatio-temporal variability in resources [1,2]. Migration occurs when the potential advantages of seasonal habitat shifts outweigh the trade-off associated with high energy expenditure and increased risk of mortality. The benefits of migration include the avoidance of predators and access to palatable, nutritious forage that is only available seasonally [3,4]. In comparison, residency, when an individual maintains a spatially constricted home range year-round rather than making seasonal movements, should theoretically occur when the costs of migration exceed the benefits. In many systems, however, the relative benefit of a given strategy may vary from year to year, 
resulting in a partially migratory population where resident and migrant behaviors co-occur within a population [5]. For example, the proportion of migratory to resident bird species in North America and Europe increases at higher latitudes where higher seasonality in available forage makes migration a more advantageous behavior [6,7]. Similar patterns have also been reported for moose (Alces alces) in Norway, where populations have an increasing propensity to migrate along a latitudinal gradient, suggesting that the likelihood of migration or residency is a product of the interannual variability of environmental conditions [8].

Climate change, expanding anthropogenic development, increasing habitat loss, and changing resource distributions have been associated with declines in ungulate migrations [9,10]. Consequential to anthropogenic development, ungulate migrations have been diminishing in proportion to residence on an annual home range [11]. Ungulate populations that remain in a spatially confined home range face heightened human-wildlife conflicts [12,13], suffer lower nutritional conditions [14], and have been tied to a higher prevalence of disease [15] compared to populations with a higher proportion of migrants. As ungulate migrations continue to decline, there will likely be demographic repercussions. When migrations are completely lost within a population, restoring the cultural knowledge of where and how to migrate can take decades to restore [16]. Thus, managing for the habitat of migratory populations to conserve the behavioral diversity of residents and migrants will be the most effective means to maintain the long-term persistence of this behavior $[17,18]$. However, despite the ecological value of migration, we still lack a complete understanding of the specific environmental attributes necessary to sustain and promote migratory populations. These patterns underscore a critical knowledge gap of the landscape-level characteristics affecting the migration-residence tradeoff. Understanding the relative importance of natural and anthropogenic features associated with different movement strategies is critical for species conservation as well as effective habitat management and restoration practices.

Mule deer (Odocoileus hemionus) are distributed across the intermountain western United States-an area facing one of the fastest rates of human settlement expansion in the country [19]. Mule deer are an important game species in North America, but their habitat is being altered or lost due to the growth of agricultural, industrial, and transportation infrastructure [20,21]. This expanding anthropogenic footprint is likely affecting migrations by limiting the ability of migratory mule deer to exploit seasonal vegetation growth within their habitats [21]. Losing the facility to migrate has long been hypothesized to scale-up to population-level consequences [22]. Indeed, management goals for mule deer emphasize the need to identify crucial habitats, such as wintering ranges, for migratory and resident populations [23]. Moreover, in 2017, the Utah Division of Wildlife Resources implemented a statewide Migration Initiative with the objective of mapping migration routes for the purpose of conserving connectivity between seasonal ranges. Furthermore, in 2018, Secretarial Order 3362 of the United States Department of the Interior emphasized the management importance of big-game winter ranges and migration corridors in western states [24]. As such, recognizing the environmental features which influence where mule deer winter, summer, or remain resident will help identify crucial habitats and potential restoration sites critical to the conservation of migratory behavior.

By integrating animal tracking and distribution modeling, we can examine the tradeoffs affecting the prevalence of migration and residence by contrasting their ecological niches [25]. We define the niche space as the environmental conditions that give rise to the seasonal migratory or resident behavior of mule deer, applying the concept of niche space to study the distribution of behaviors [26]. The relative abundance of mule deer and their behavioral fidelity [27] creates a valuable opportunity to study how environmental differences are associated with migratory and resident behavior, which will help inform managers of both mule deer and other migratory ungulates of the specific environmental attributes necessary to sustain and promote migratory populations. Here, we evaluate the differences in niche space associated with migrant and resident behavior to (a) better understand the contributing factors influencing the tradeoff of partial migration, and then (b) visually identify essential habitats for conserving mule deer subpopulations. Our analysis can help elucidate how changes in land use may sway the tradeoffs in either direction. 
Given the large-scale changes affecting mule deer habitats, our research relies extensively on remote sensing as a tool to visualize, quantify, and understand how landscape-level changes are affecting available niches for mule deer. Satellite remote sensing has been used widely to measure many aspects of wildlife habitat quality, including vegetation productivity, water sources, snow cover, and anthropogenic development (e.g., settlements and transportation networks) [28,29]. In addition, when combined with GPS-tracked animal movement data, remote sensing provides an unprecedented opportunity to study the spatial distribution of migratory and resident niches.

\section{Methods}

\subsection{Study Area}

All mule deer were collared from mountain populations in Utah. Our study area ranges from $38^{\circ} \mathrm{N},-112^{\circ} \mathrm{W}$ to $40^{\circ} \mathrm{N},-110^{\circ} \mathrm{W}$ (ca. $150 \mathrm{~km}$ by $300 \mathrm{~km}$ ), including the Wasatch, Monroe, and Oquirrh mountain ranges in central Utah (Figure 1). The elevation ranges from a minimum of $1292 \mathrm{~m}$ to a maximum of $3607 \mathrm{~m}$ [30]. The landscape represents a longitudinal transition zone from the Great Basin to the Colorado Plateau ecoregion, where higher elevation communities (>2200 m) are characterized by mixed conifer (Picea sp., Abies sp., Pinus sp.) and aspen (Populus tremuloides) forests. Intermediate elevations in more arid sites support piñon-juniper (Pinus edulisi, Juniperus sp.) forests or sagebrush ecosystems (Artemisia tridentata, Purshia sp., Amelanchier sp., and Cercocarpus sp.) [31]. Growing seasons in this ecoregion are often determined by the elevational gradient, as higher-elevation woodlands tend to green later and faster than the lowlands. Likewise, estimates for primary productivity are greater in high-elevation woodlands than lower elevations [32]. This region is undergoing population growth twice the national average, with commensurate increases in land use from urban and exurban sprawl and agriculture [33].

\subsection{Animal Locations and Migratory Habitat}

We analyzed the locations of 42 mule deer from three populations located in the Wasatch, Monroe, and Oquirrh mountains, collected between 2010 and 2015 by GPS telemetry. The total number of relocations was $\mathrm{N}=155,823$, with an average $\mathrm{N}=3710$ per individual mule deer. In the Wasatch mountain range, 15 mule deer were captured in December 2010 and tracked until December 2012 [34]. In the Monroe range, 14 mule deer were tracked from either March 2012 or March 2013 until 2015. For the 13 mule deer in the Oquirrh range, data collection spanned January-February 2012 and continued until 2014. Individuals from the Monroe and the Oquirrh mountains had GPS locations recorded at three-hour intervals, and individuals from Wasatch had eight-hour time intervals. We minimized errors by removing the upper 5 th percentile of the recorded horizontal dilution of precision (HDOP) relocations for each individual (C. Fleming, pers com).

\subsection{Classification of Movement Points}

We classified individuals as either "migratory" or "resident" by visually interpreting net squared displacement (NSD) plots, where the NSD averages the individual's change in distance traveled from the first collection point over time. For example, an NSD plot exhibiting multiple leveled-off 'plateaus' with distinct spikes in movement between the plateaus is indicative of migratory behavior, and plots that only approach an asymptote with no distinct movements between ranges are indicative of resident behavior (Figure 2) [8,35]. NSD plots demonstrate the timing of migration as either autumn (September-December) or spring (February-May). For every individual, we classified all their locations as either perennial resident, summer migratory, or winter migratory depending on the migratory status of the individual and the timing of migration (i.e., whether the locations were after autumn or spring migration). We removed any location data that occurred during migration and only used individuals with at least seven months of continuous GPS fixes to ensure full coverage of at least two seasons by 
each sampled animal. We visually inspected semi-variograms of each individual mule deer to further verify our NSD classifications of migrants and residents (See Supplementary Material Figure S1).

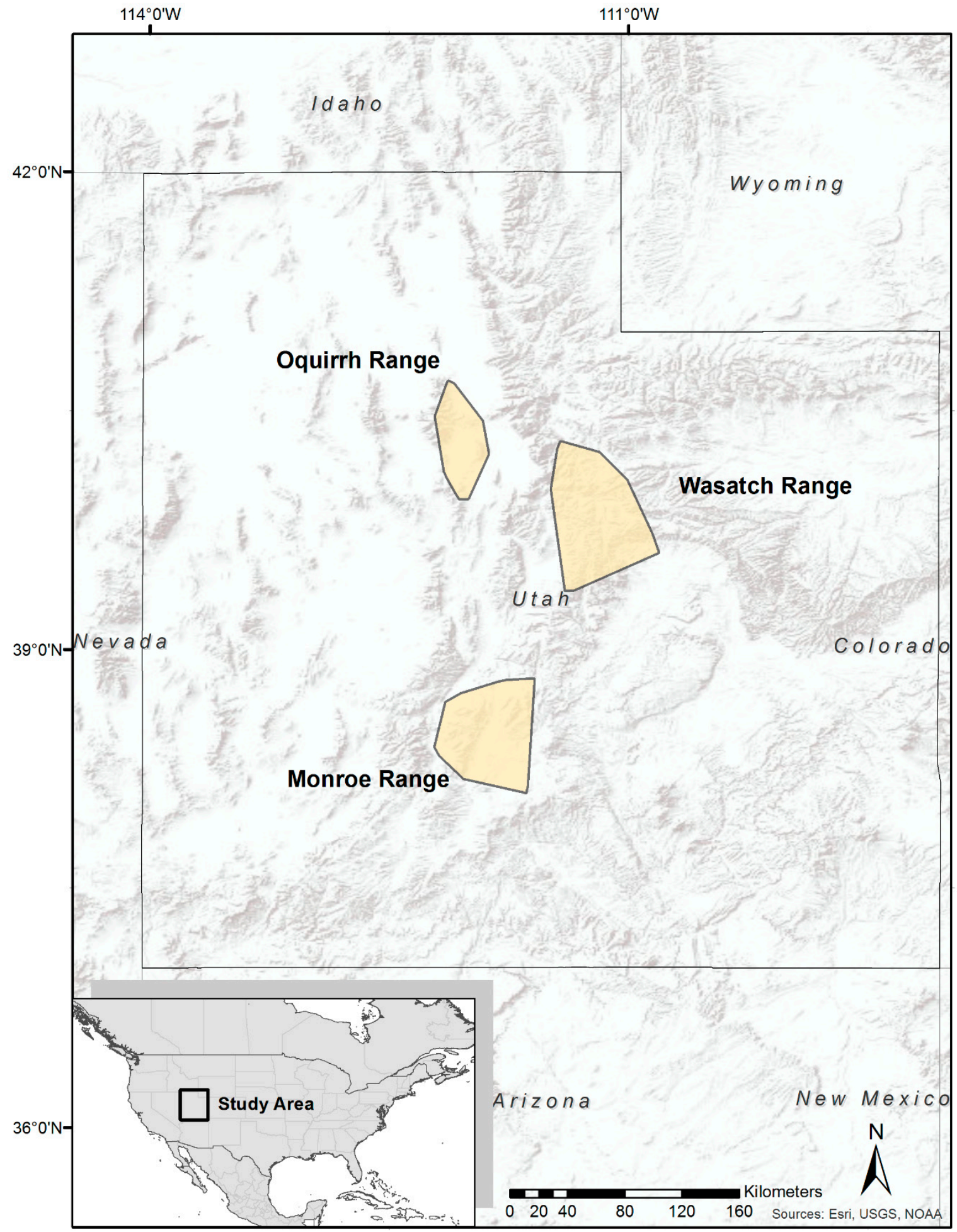

Figure 1. Study area. This study includes three distinct population ranges of mule deer. The Oquirrh range included 13 GPS-collared mule deer monitored between 2012 and 2014. The Monroe range included 14 GPS-collared mule deer monitored between 2012 and 2015, and the Wasatch range included 15 GPS-collared mule deer monitored between 2010 and 2012. 

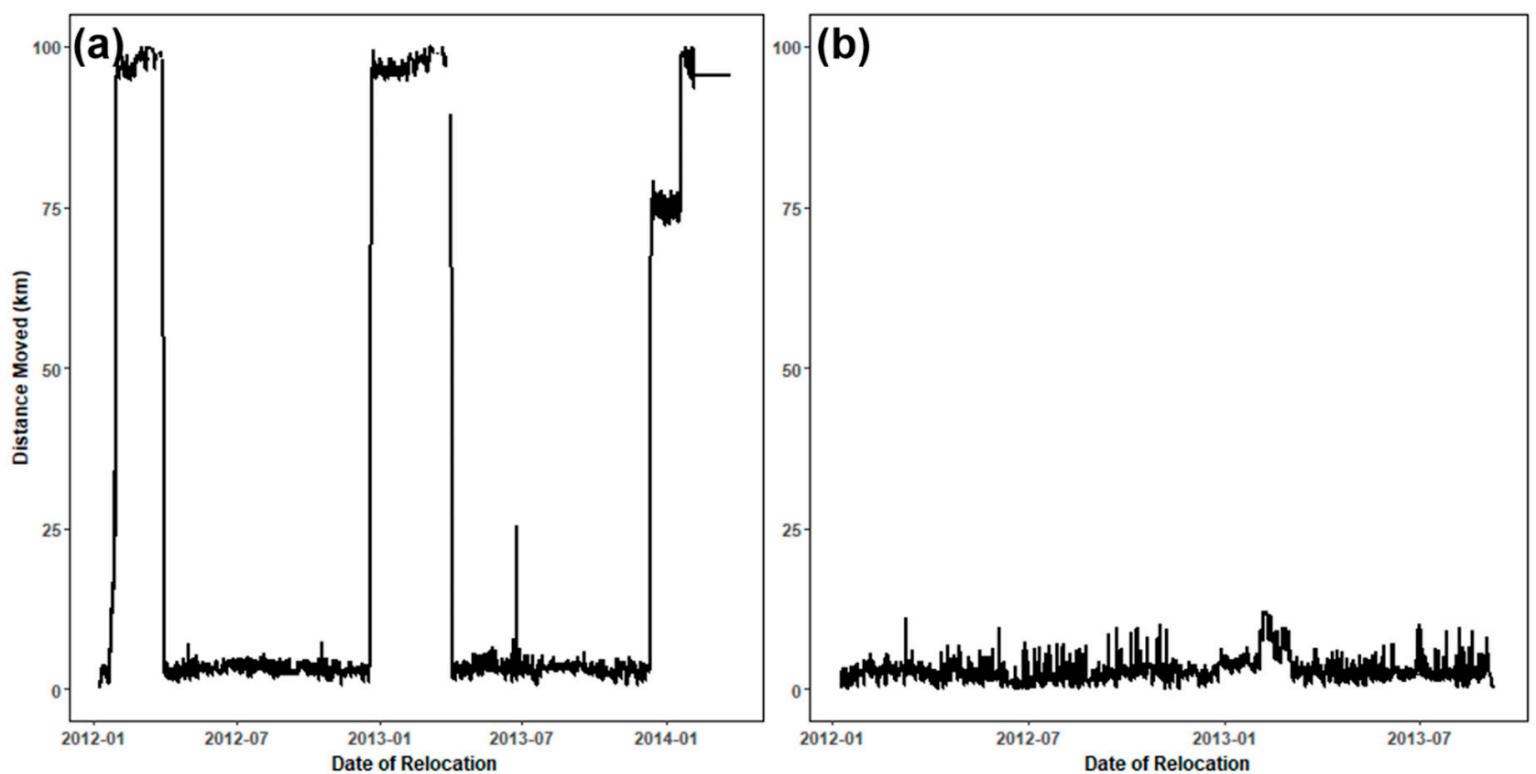

Figure 2. Net squared displacement of migratory and resident deer. The x-axis is the date of each relocation from the GPS data, and the y-axis is the displacement in kilometers from the first collected point. (a) The peaks and valleys demonstrate a clear migratory pattern in the net squared displacement, with the first migration occurring just after January 2012. (b) The relationship demonstrates little change from the initial relocation, suggesting a resident movement pattern displayed by the deer.

\subsection{Predictive Environmental Variables}

To develop seasonal niche models, we included variables that describe forage quality, snow cover, elevation, as well as distances to water, wetlands, agriculture, and development (Table 1). We used 16-day composites of the normalized difference vegetation index (NDVI) [36,37], derived from MODIS/Terra satellite imagery at $250 \mathrm{~m}$ spatial resolution [38], to quantify forage quality. NDVI has been widely used as an index for ungulate forage because it measures photosynthetically active vegetation to model gross primary productivity $[36,37,39]$. To minimize interannual variability, we averaged NDVI data by month between 2010 and 2015, resulting in 12 monthly NDVI averages (Table 1). Because previous studies have demonstrated the importance of interannual variation in phenology to animal movement, we also calculated the monthly standard deviation between 2010 and 2015 [2] (Table 1).

We used daily measurements of the normalized difference snow index (NDSI) [40], derived from MODIS/Terra satellite imagery at $500 \mathrm{~m}$ spatial resolution [41], to quantify the extent of snow cover. We included snow cover because it can significantly influence ungulate ecology through movement costs and loss of forage availability [42-44]. We averaged NDSI data by month between 2010 and 2015 (Table 1).

We included elevation from the Shuttle Radar Topography Mission (SRTM) Digital Elevation Model [30] to assess the importance of elevation for migration [45]. To include other important land cover variables, we extracted water, wetlands, agriculture, and development from the National Land Cover Database (NLCD 2011) [46]. The NLCD 2011 dataset is available from the Multi-Resolution Land Characteristics Consortium and uses Landsat Thematic Mapper images to produce a $30 \mathrm{~m}$ spatial resolution classification. We measured distance to NLCD-classified wetlands, water, agriculture, and development to quantify water availability and the intensity of potential anthropogenic influence. Although landcover classifications can include intrinsic errors, the clear spectral signals between development, agriculture, water, and wetlands gives us confidence that these predictors are not an artefact of erroneous classification. 
Table 1. Variables included in the random forest model. Listed are all variables used in the model, the ecological justification for their inclusion, and previous studies demonstrating the use of such variables.

\begin{tabular}{|c|c|c|}
\hline Variable Name & Class of Variable & Description and Data Source \\
\hline $\begin{array}{c}\text { NDVI } \\
\text { January-December }\end{array}$ & Phenology & $\begin{array}{l}\text { The average normalized difference vegetation index (NDVI), } \\
\text { calculated from MODIS Terra [36,37]; } \\
\qquad \overline{N D V I}_{\text {Month }}=\frac{\sum_{2010}^{2015}\left(N D V I_{M o n t h}\right)}{N} \\
\text { where N is the total number of NDVI MODIS Terra } \\
\text { observations for each of the } 12 \text { months between } 2010 \text { and } 2015 . \\
\text { There were two NDVI observations per month across the five } \\
\text { years, with N = } 10 \text { for each monthly NDVI layer. }\end{array}$ \\
\hline $\begin{array}{l}\text { NDVISD } \\
\text { January-December }\end{array}$ & Phenology & $\begin{array}{l}\text { Variability calculated as the monthly standard deviation in } \\
\text { NDVI from MODIS Terra satellite imagery }[36,37] \\
\qquad N D V I S D_{M o n t h}=\sqrt{\frac{\sum_{2010}^{2015}\left(N D V I_{M o n t h}-N D V I_{M o n t h}\right)^{2}}{N-1}} \\
\text { where N is the total number of NDVI MODIS Terra } \\
\text { observations for each of the } 12 \text { months between } 2010 \text { and } 2015 . \\
\text { There were two NDVI observations per month across the five } \\
\text { years, with N = } 10 \text { for each monthly NDVI layer. }\end{array}$ \\
\hline $\begin{array}{l}\text { NDSI } \\
\text { January-December }\end{array}$ & Snow cover & $\begin{array}{l}\text { The average normalized difference snow index (NDSI), } \\
\text { calculated from MODIS Terra satellite imagery [40] } \\
\qquad \overline{N D S I}_{M o n t h}=\frac{\sum_{2010}^{2015}\left(N D S I_{\text {Month }}\right)}{N} \\
\text { where N is the total number of NDSI MODIS Terra } \\
\text { observations for each of the } 12 \text { months between } 2010 \text { and } 2015 \text {. } \\
\text { There were daily NDSI observations across the five years, so } \\
\text { for each year there were } 31 \text { observations between } \\
\text { January-November, and } 21 \text { for December. }\end{array}$ \\
\hline $\begin{array}{l}\text { Distance to } \\
\text { development }\end{array}$ & Land cover & $\begin{array}{l}\text { The distance to the nearest edge of development was } \\
\text { calculated from the National Land Cover Dataset } 2011 \text { [46] }\end{array}$ \\
\hline Distance to water & Land cover & $\begin{array}{c}\text { The distance to the nearest edge of water was calculated from } \\
\text { the National Land Cover Dataset } 2011 \text { [46] }\end{array}$ \\
\hline $\begin{array}{l}\text { Distance to } \\
\text { wetlands }\end{array}$ & Land cover & $\begin{array}{l}\text { The distance to the nearest edge of wetlands was calculated } \\
\text { from the National Land Cover Dataset } 2011 \text { [46] }\end{array}$ \\
\hline $\begin{array}{l}\text { Distance to } \\
\text { agriculture }\end{array}$ & Land cover & $\begin{array}{l}\text { The distance to the nearest edge of agriculture was calculated } \\
\text { from the National Land Cover Dataset 2011 [46] }\end{array}$ \\
\hline Elevation & Elevation & $\begin{array}{c}\text { Digital Elevation Model from the NASA Shuttle Radar } \\
\text { Topography Mission [30] }\end{array}$ \\
\hline
\end{tabular}

\subsection{Model Setup}

We discriminated niche types of mule deer with a random forest classifier [47], a non-parametric machine learning algorithm that can handle a large array of variables and can achieve higher accuracies in modeling complex responses than many parametric models because it requires no assumptions of the underlying distributions in the predictors or response variables. Random forest is also less prone to overfitting than simple classification trees because of the randomization and out-of-the-bag error estimation algorithms [48]. Additionally, random forest models rank the feature contributions of the variables through permutations, meaning that the method is well suited for our study's purpose of observing the tradeoff of environmental conditions between resident and migrant behaviors. To minimize bias from correlated predictors, we fit multiple random forest models with different values for the mtry parameter, which designates the number of randomly selected predictors to use when constructing each decision tree in the model $(6,10,15,20,25$, and 30) [49]. In the final analysis, we selected the random forest model which allowed for 25 randomly selected predictors to build each tree $(m t r y=25)$, as this was the first model where the variable importance had the same five most important variables after a fit of 3000 trees, suggesting model stabilization and minimal bias from multicollinearity given the consistent top five variables in the ranking.

We trained the random forest classifier using the predictive variables extracted at movement locations. The random forest model "grows" a specified number of classification trees, and each tree provides a classification prediction based on randomized subsets of training data and predictive 
variables. The model determines the classification result by selecting the class that receives the majority of the vote among all trees. We later used the votes of each tree in the random forest model to assess predictions with highest certainty (see Section 2.6). To cross-validate, we reran the model, randomly holding the GPS relocations of ten individual mule deer out of the model building step as references. We assessed the cross-validated accuracy of the random forest model through the prediction accuracy and kappa value, a measure of agreement in classification relative to the random assignment of classes, with a higher kappa value suggesting a higher accuracy of the model. The variable importance and predictive maps all used the full random forest using the entire dataset of 42 mule deer.

\subsection{Prediction and Mapping Migratory/Resident Niches}

To predict niche types across Utah, the full random forest model was applied to the geospatial variables covering the extent of the state. To remove areas deer were unlikely to use, we masked the predictive surface to include only known mule deer habitats [50]. Additionally, we removed the predictions where the proportion of agreed classification in the random forest was less than 0.8 to visualize where the model had the most predictive certainty.

To address potential autocorrelation in the model, we reran ten random forest models, each missing one of the top ten most important variables from the full dataset, then compared the 'take-one-out' model projection with the original full model projection using the balanced accuracy (the average of true positive rate and the true negative rate). A negative percentage change in balanced accuracy means the prediction accuracy deteriorates with the removal of that predictor from the model, and a positive percentage change in balanced accuracy means the prediction accuracy improves with the removal of that predictor. All modeling and data preparation was carried out within the R system for statistical computing [51]. Random forest models were available through the 'randomForest' package [52].

\section{Results}

Individual NSD figures allowed us to separate the dataset into 11 resident $(\mathrm{N}=54,779$ resident GPS relocations, 35\% of the relocation dataset,) and 31 migratory mule deer ( $\mathrm{N}=33,186$ migratory GPS relocations on summer range, $21.3 \%$ of the relocation dataset, and $\mathrm{N}=67,858 \mathrm{GPS}$ relocations on winter range, $43.5 \%$ of the relocation dataset). Using the full dataset, the random forest classification had a prediction accuracy of $97.87 \%$ and kappa value of 0.97 . Rerunning the model with cross-validation, withholding ten individuals (two residents and eight migrants) produced a prediction accuracy of $81.23 \%$ and a kappa value of 0.75 . From the cross-validation, the probability that our model correctly classified mule deer habitats was highest for the resident niche (true positive rate or sensitivity $=0.93$, true negative rate or specificity $=0.97$ ), followed by the winter migratory niche (true positive rate $=0.87$, true negative rate $=0.77$ ), and then the summer migratory niche (true positive rate $=0.58$, true negative rate $=0.96)($ Table 2$)$.

Table 2. Confusion matrix of cross-validation relocation data showing the number of instances that the random forest correctly and incorrectly classified GPS data, where the reference is the actual habitat type and the estimation column is how the model classified the location.

\begin{tabular}{|c|c|c|c|c|}
\hline & & $\begin{array}{c}\text { Resident } \\
\text { Habitat }\end{array}$ & $\begin{array}{c}\text { Actual } \\
\text { Summer } \\
\text { Migratory Habitat }\end{array}$ & $\begin{array}{c}\text { Winter Migratory } \\
\text { Habitat }\end{array}$ \\
\hline \multirow{3}{*}{ Predicted } & Resident Habitat & 10,510 & 1 & 718 \\
\hline & Summer Migratory Habitat & 1 & 5356 & 1155 \\
\hline & Winter Migratory Habitat & 850 & 3809 & 12,403 \\
\hline
\end{tabular}

The four most important variables in the random forest model were the distance to development, followed by average snow cover in December, distance to water, and distance to agriculture (Figure 3). These four predictors were consistently the most important variables when we tested the variable 
importance of the take-one-out random forests (Supplementary Material Figure S2). Of the ten most important variables in the random forest, only two variables (NDSI February and NDSI December) had a Pearson's correlation coefficient greater than 0.7 (Supplementary Material Table S1). Collinear predictors can bias results of variable importance in random forests [49]; however, the collinearity between average NDSI in February and December does not affect our ability to interpret the random forest because of the close relationship between these two predictors. The collinearity between these predictors did not inflate the random forest's prediction accuracy, as indicated below in the take-one-out analysis. By observing the environmental features of the classified GPS data used to train the random forest model, resident niche space was often closer to developed areas than either summer or winter migratory niches (Figure 4). Summer migratory niches tended to have a higher average snow cover in December and were further from agriculture than either resident or winter migratory niches.

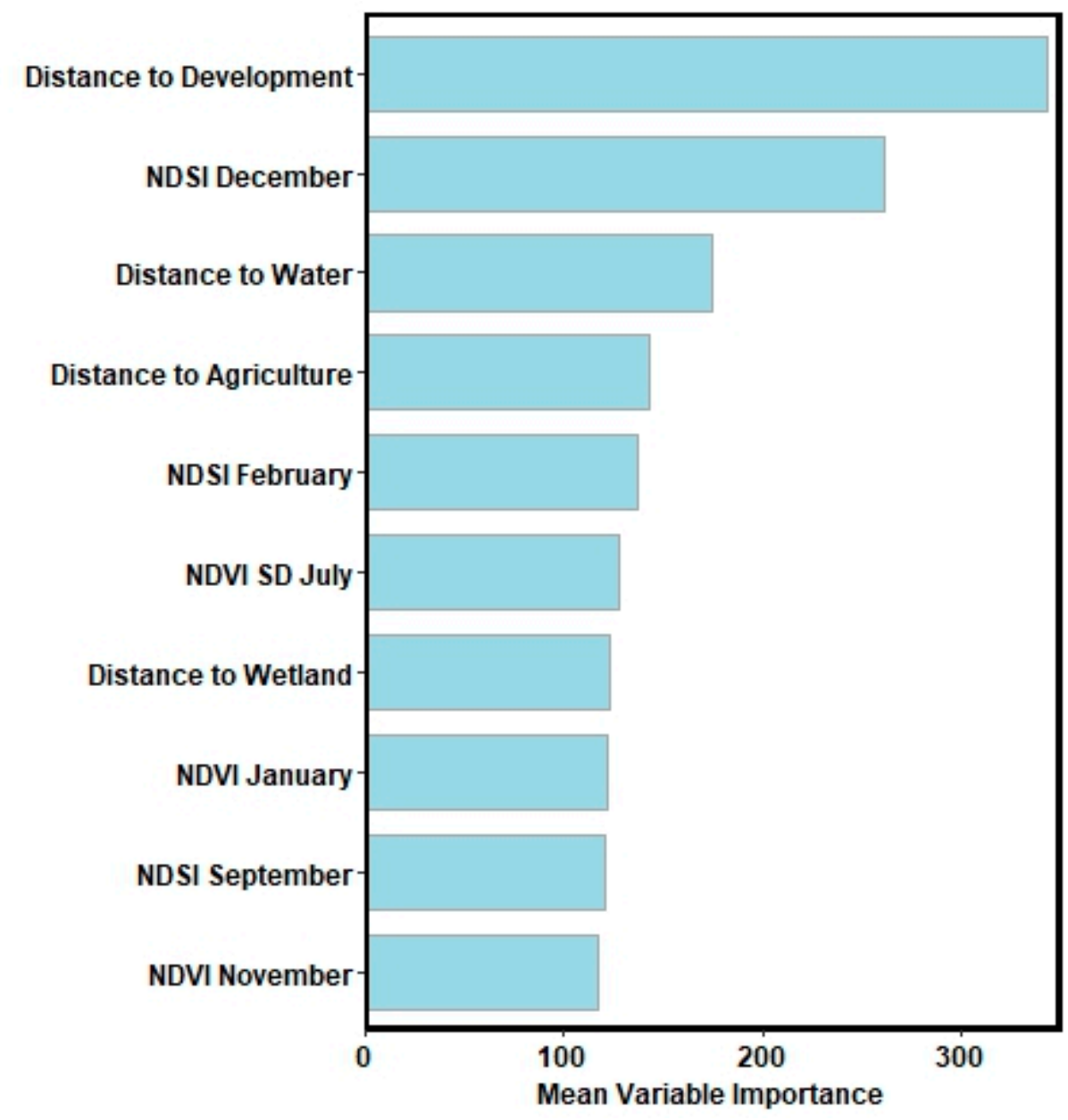

Figure 3. Variable importance by permutation accuracy. The random forest model assesses the importance of every variable used in the model. A larger mean variable importance (x-axis) gives evidence of a larger contribution of that individual variable in correctly discriminating the habitat type. Here, only the top ten most important variables are shown: distance to development, snow cover (NDSI) in December, distance to water, distance to agriculture, snow cover (NDSI) in February, standard deviation in vegetation (NDVI SD) in July, distance to wetlands, vegetation cover (NDVI) in January, snow cover (NDSI) in September, and vegetation cover (NDVI) in November. 

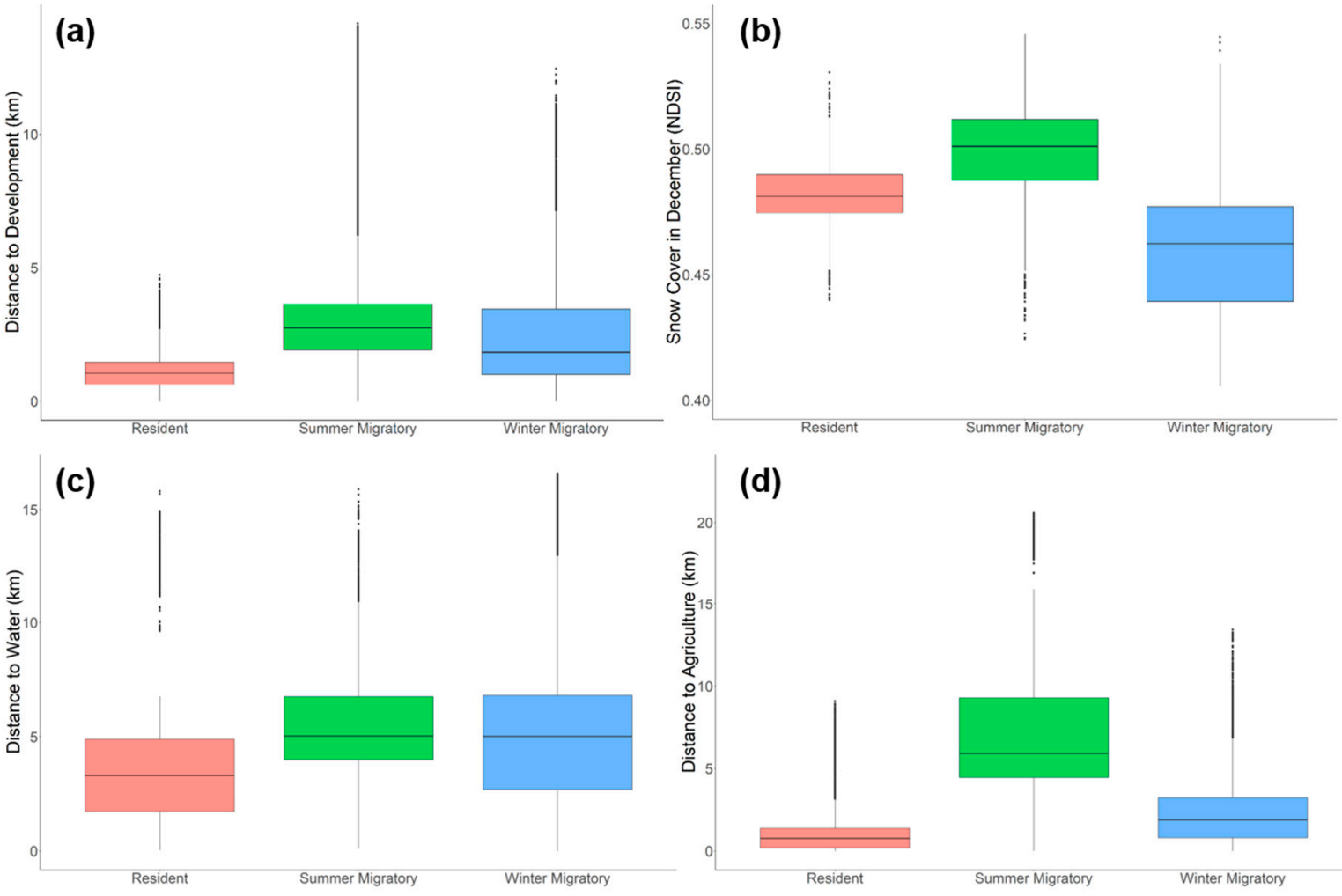

(d)

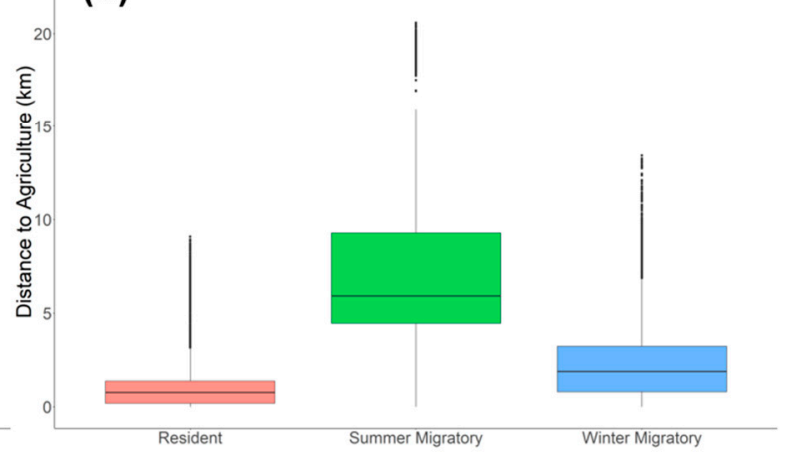

Figure 4. Environmental covariates of the four most important variables in the random forest, where the red boxplots designate the resident niche, green designates the summer migratory niche, and blue designates the winter migratory niche. (a) Distance to development, (b) snow cover (NDSI) in December, (c) distance to water, and (d) distance to agriculture.

The resident niche space was estimated to cover $5.81 \%\left(7032 \mathrm{~km}^{2}\right)$ of the area designated as mule deer habitat $\left(120,915 \mathrm{~km}^{2}\right)$ (Figure 5). The migratory summer niche space was estimated to cover $36.02 \%$ of deer habitat $\left(43,554 \mathrm{~km}^{2}\right)$ and migratory winter niche space was estimated to cover $58.16 \%$ of deer habitat $\left(70,328 \mathrm{~km}^{2}\right)$. The total predicted niche space with highest certainty $(0.8$ or higher agreement in votes) covered $25.37 \%$ of deer habitat $\left(30,674 \mathrm{~km}^{2}\right)$, resident niche space made up $0.89 \%$ of deer habitat $\left(1080 \mathrm{~km}^{2}\right)$, and migratory summer and winter niche space made up $6.73 \%\left(8140 \mathrm{~km}^{2}\right)$ and $17.74 \%\left(21,455 \mathrm{~km}^{2}\right)$ of deer habitat, respectively. This meant that only retaining areas with high predictive certainty led to model predictions being reduced by $84.65 \%$ for resident niche space, $84.31 \%$ for summer migratory niche space, and $69.49 \%$ for winter migratory niche space.

Individually removing each of the ten most important variables resulted in minimal differences in prediction accuracy across predicted niches (Figure 6). Across the three predicted niches, removing the distance to development had the greatest predictive deterioration compared to the full model, where summer migratory niches had a $-0.023 \%$ change in balanced accuracy. The random forest's predicted accuracy improved the most for the summer migratory niche when NDVI in November was removed (change in balanced accuracy of $0.012 \%$ ). Removing either of the collinear predictors NDSI in February and NDSI in January had a minimal effect on prediction accuracy, suggesting that their collinearity did not inflate prediction confidence. 


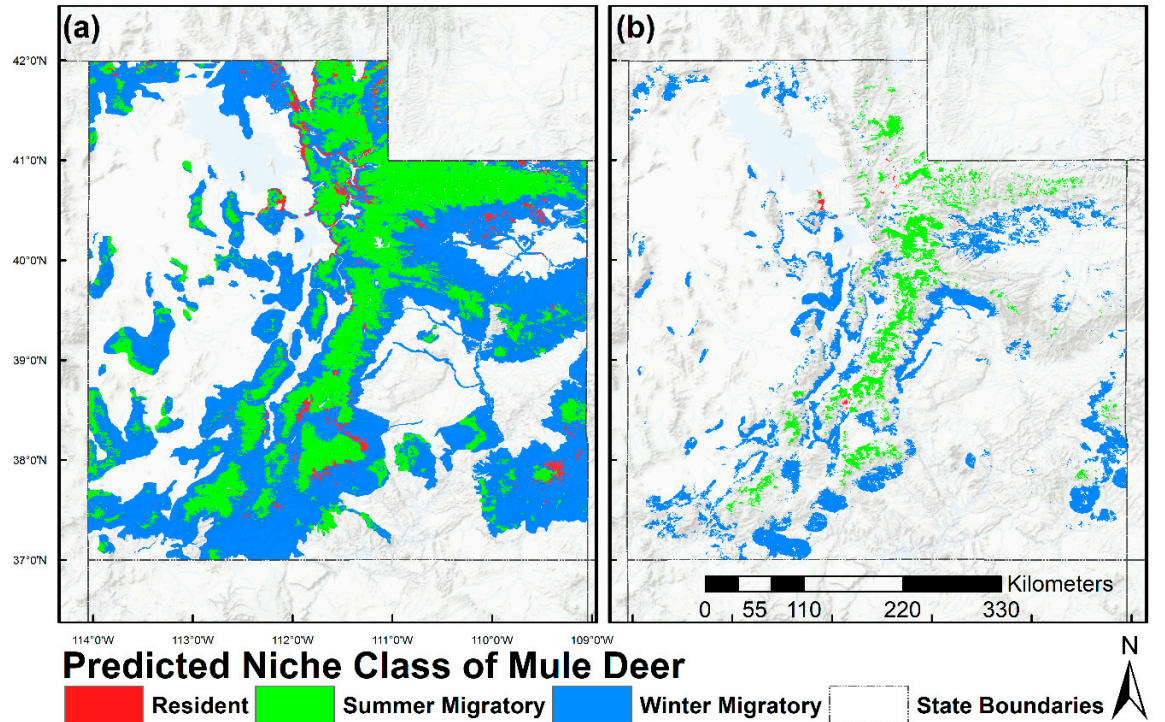

Figure 5. Predicted migratory and resident niche classes in Utah. (a) Random forest classification across the entire state within known mule deer habitat. (b) Random forest classification where there was high certainty in prediction (proportion of agreed classes greater than 0.8 ). Red designates areas discriminated as resident niches, blue designates winter migratory niches, and green designates summer migratory niches.

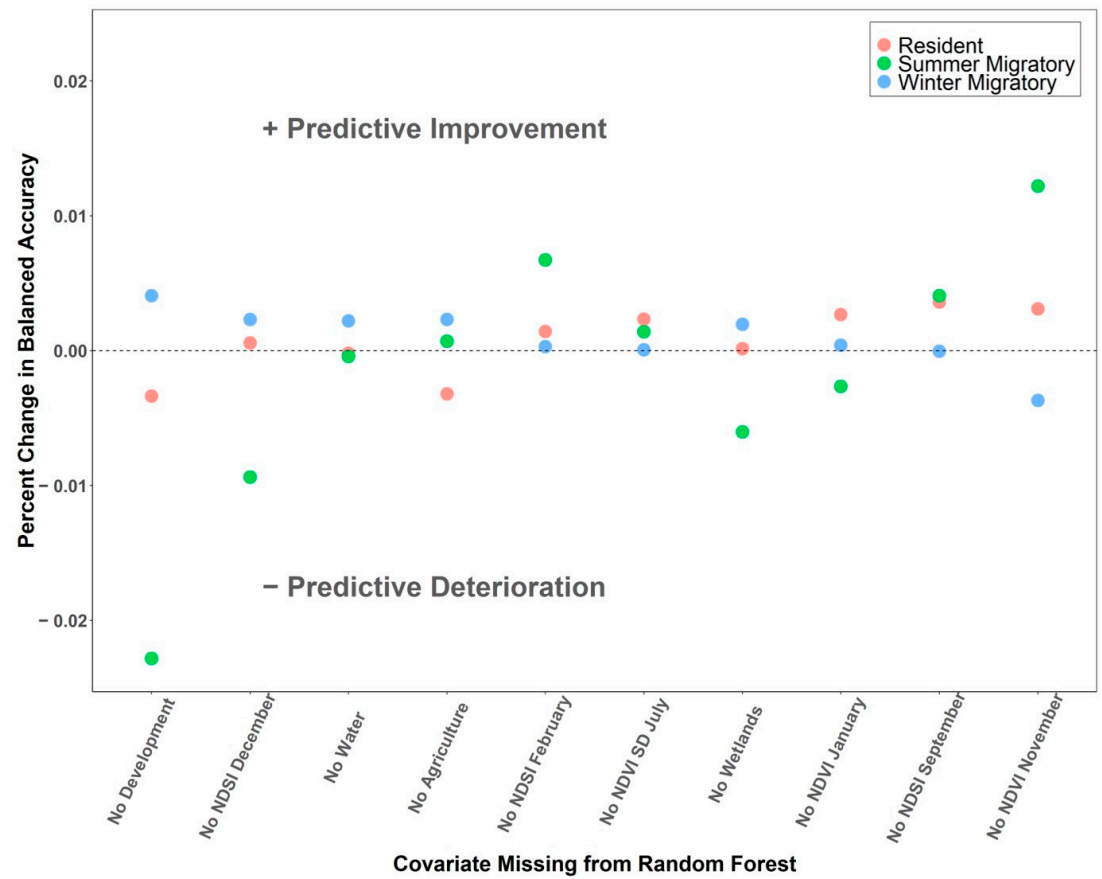

Figure 6. The changes in balanced accuracy with the take-one-out random forest method. After running the initial random forest, we reran ten random forests, each missing one of the ten top ranked variables from the initial random forest, to further assess the importance of each variable. To quantify how removing these predictors affected the prediction, from each random forest, we calculated the balanced accuracy (average of the true positive rate and the true negative rate) of the confusion matrix for the full dataset of 42 mule deer. We then calculated the percentage change in the balanced average for each predicted niche type by comparing this with the initial random forest, including all variables. A negative percentage change demonstrates worse predictive accuracy by removing the given predictor from the model. Red points are predicted resident niches, green points are predicted summer migratory niches, and blue points are predicted winter migratory niches. 


\section{Discussion}

Given the large-scale changes affecting mule deer habitats, our research relies extensively on remote sensing as a tool to visualize, quantify, and understand how landscape-level changes are affecting available niches for resident and migratory mule deer. We combined remotely sensed environmental data with GPS-tracked mule deer movement data to examine spatial patterns of resident and migratory mule deer niches. The classification showed overall high accuracy for discriminating resident, winter migratory, and summer migratory niche space.

Anthropogenic features of the landscape were the most important variables to differentiate winter migratory, summer migratory, and resident niche space. Residents were found closer to developed areas than migrants on summer or winter ranges. This relationship between developed areas and residence was further supported with the take-one-out analysis, where removing distance to development resulted in the greatest deterioration in prediction accuracy. Thus, differentiating between summer migratory and resident niches depended in part on the proximity of habitat to developed areas. Two non-mutually exclusive hypotheses may explain this pattern. First, this result may be attributed to barrier effects: key migratory routes tend to include geographic bottlenecks that can be further narrowed by encroaching development, restricting movement [53]. Encroaching development can effectively cutoff migration by creating impermeable barriers, which has raised concerns over the future viability of populations that occupy habitats that are unsuitable during winter [9]. Alternatively, ungulates may actively select for development to access preferred forage. For example, in mixed-use landscapes, some elk (Cervus canadensis) populations have abandoned migration when near developed or agricultural areas, where the availability of perennial forage and low predation risk may outweigh the costs of residence [13]. Additionally, late summer forage quality can be higher in resident habitats than summer migratory habitats for elk [54]. Moderate development can attract deer because of year-round irrigated vegetation and agricultural crops with high caloric content, such as alfalfa $[55,56]$. Importantly, these hypotheses are not mutually exclusive. Distance to agriculture being selected as one of the most important variables might suggest that mule deer habitat is being supplemented by agriculture. Globally, the degree of wildlife movement has been decreasing as a result of increasing development [57]. Understanding the degree to which this trend is attributable to barrier effects and/or anthropogenic supplementation will help elucidate the mechanisms influencing the global trend of decreasing terrestrial migrations, and therefore provide the best methods to managers interested in conserving migrations.

Despite some overlap in space, our model was able to discriminate between three different seasonal niches related to mule deer behavior. Migratory mule deer can overlap with residents while on winter ranges [43]; however, in our study, there was higher misclassification in the RF model between seasonal migratory niches, which may have been a result of the variability in seasonal niche characteristics selected by individual migrants. Along with the variability embedded in the migratory niche data (due to the larger sample size and larger niche area of migrants), the higher misclassification of seasonal migratory niches may have resulted from region-specific habitat cues (e.g., spring phenology, snowmelt, and elevational gradients) driving differences between migratory summer and winter niches. Our classification assumed omniscience in how mule deer perceive their landscapes as well as absolute values for niche selection across the study area; however, terrestrial migrants have a limited extent of perception and so depend on memory cues and culture to alleviate these limitations [58]. Confined spatial perception suggests that migratory mule deer might select seasonal niches based on relative differences in environmental gradients, rather than absolute thresholds over the landscape. Additionally, memory cues remain poorly studied in terrestrial migrations even though mechanisms of memory likely have an important influence on migratory niche selection [58]. Controlling for region-specific or herd-specific differences as well as incorporating memory as a mechanism of niche selection will likely improve the classification accuracy of future studies.

The timing of ungulate migration is often synchronized with forage maturation and snow cover, as many migratory ungulates move from summer to winter habitats once there is a significant 
accumulation of snow and move from winter to summer habitats to follow the elevational gradient of vegetation greening $[3,59,60]$. Our study did not directly test hypotheses related to the synchronization of migration initiation to environmental gradients; nonetheless, the high importance of snow cover in December in our model highlights the significance of climatic events taking place at the onset of autumn migration (late November and mid-December). The vegetation and snow cover condition at the beginning of the spring migration (between March and May) had relatively lower importance for the classification of migratory summer and winter ranges, suggesting that such environmental gradients initiating spring migrations may be more important to the selection of migratory corridors rather than summer and winter ranges. Future study may improve upon predicting the spatial patterns of mule deer by incorporating alternative remotely sensed metrics for forage quality, such as the fraction of photosynthetically active radiation absorbed (fAPAR) [61]. However, the metric of NDVI remains ubiquitous in migration ecology because of its high predictive accuracy for ungulate movement $[3,4,39,60,62]$. Attributes of how spring phenology progresses through a landscape (measured by NDVI) can promote the persistence of terrestrial migrations (the 'greenscape' hypothesis) through migration corridors [60]. Although we did not classify migratory corridors and removed location data of mule deer on corridors, our results suggest that attributes of environmental gradients such as spring phenology may be more important in the selection of migratory corridors rather than migratory summer and winter ranges.

Terrestrial migrations are disappearing on a global scale $[9,11]$, and efforts to accommodate large-scale animal migrations require a better understanding of the environmental influences affecting the prevalence of this behavior [10]. The results of our study produce spatially explicit information that can be applied to managing mule deer habitats at different locations and provide insight into the environmental mechanisms that are associated with the transition between resident and migratory behaviors. Moreover, because random forest models provide an intuitive metric for the certainty in predictions (from the proportion of agreed classification trees), habitat management of migratory species can better identify crucial habitats where the model is most certain. The remote sensing we used here to spatially identify seasonal niche locations for mule deer has value in land management practices, providing tools to identify crucial winter ranges for migratory mule deer herds, and can be extrapolated to where migratory mule deer might still persist. The broad-scale visualization can additionally be used to assist in setting or adjusting hunting seasons. In Utah, mule deer hunting permits are allocated on the basis of pre-defined management units. The number of permits issued each year is partly determined by abundance, a variation which is strongly influenced by drought and winter severity [23]. Identifying the timing and routes of migratory herds can potentially help improve the accuracy of the population estimates and seasonal distributions.

\section{Conclusions}

We show that the remote sensing of landscape variables across a large spatial and temporal scale can provide important insights into trade-offs between migration and residence in mule deer. Anthropogenic development has an explanatory value in predicting resident habitats where locations closer to development were more likely to be used by resident mule deer, while December snow cover had more explanatory power in predicting summer migratory niches, as locations with higher snow cover tended to be used only in the summer by migratory mule deer. Our results provide a useful groundwork to identify seasonal niches using remotely sensed environmental data. Merging the advances of remote sensing and landscape ecology will improve our understanding of how to conserve migratory behavior in North America and elsewhere and provide insight into scientifically grounded land management decisions for migratory ungulates. Wildlife management can make use of the tools of remote sensing and landscape ecology to identify crucial seasonal habitats for highly mobile wildlife populations.

Supplementary Materials: The following are available online at http://www.mdpi.com/2072-4292/11/17/1980/s1, Figure S1: Semivariograms of example migratory and resident mule deer. These semivariograms were created to 
verify our visual inspection of net squared displacement plots. Panel a demonstrates a migratory mule deer, as the semivariance fluctuates throughout. Panel $b$ is of a resident mule deer because the semivariance levels off and remains relatively constant, Table S1: Correlation matrix. To elucidate collinearity between the variables used in the random forest model, we analyzed the correlation between the top ten most important variables selected by the model. Values range between -1 and 1 , demonstrating either a perfect negative or positive linear trend between the variables. Here, the highest correlation is between NDSI December and NDSI February. Figure S2: Variable importance of the full random forest and the take-one-out random forests, each missing one of the top ten most important predictors. The $\mathrm{x}$-axis and $\mathrm{y}$-axis are the mean decrease in accuracy, so a large mean decrease in accuracy suggests higher importance to the random forest. Across random forests, distance to development was always the most important variable and snow cover in December the second most important variable when they were available (i.e., not removed from the take-one-out random forest).

Author Contributions: Conceptualization, B.R. and Q.H.; methodology, B.R. and Q.H.; writing-original draft preparation, B.R.; writing-review and editing, Q.H., J.S., D.S., and P.L.; supervision, Q.H. and P.L.; funding acquisition, Q.H., J.S., and P.L.

Funding: This research was funded by the University of Maryland, Smithsonian SEEDs grant.

Acknowledgments: The Utah Division of Wildlife Resources provided animal data and logistical support (Federal Aid in Wildlife Restoration Program, grant nos. W-65-M, W-170-R). Additional financial, logistical, and organizational support was provided by the NASA Biodiversity and Ecological Forecasting Program (Climate and Biological Responses, grant no. NNH10ZDA001N), the Utah Army National Guard, Kennecott Utah Copper Corporation, the US Geological Survey, Utah's Hogle Zoo, and the Utah Chapter of the American Association of Zoo Keepers. Special thanks to D. Olson, K. Hersey, J. Shannon, V. Mumford, A. Aoude, B. Bates, A. Neville, K. Rasmussen, J. Crane, D. Johnson, L. Larson, J. Stabach, C. Fleming, W. Xu, and T. Edwards.

Conflicts of Interest: The authors declare no conflict of interest.

\section{References}

1. Fryxell, J.M.; Greever, J.; Sinclair, A.R.E. Why are migratory ungulates so abundant? Am. Nat. 1988, 131, 781-798. [CrossRef]

2. Mueller, T.; Olson, K.A.; Dressler, G.; Leimgruber, P.; Fuller, T.K.; Nicolson, C.; Novaro, A.J.; Bolgeri, M.J.; Wattles, D.; DeStefano, S.; et al. How landscape dynamics link individual-to population-level movement patterns: A multispecies comparison of ungulate relocation data. Glob. Ecol. Biogeogr. 2011, 20, 683-684. [CrossRef]

3. Bischof, R.; Loe, L.E.; Meisingset, E.L.; Zimmermann, B.; Van Moorter, B.; Mysterud, A. A migratory northern ungulate in the pursuit of spring: Jumping or surfing the green wave? Am. Nat. 2012, 180, 407-424. [CrossRef] [PubMed]

4. Merkle, J.A.; Monteith, K.L.; Aikens, E.O.; Hayes, M.M.; Hersey, K.R.; Middleton, A.D.; Oates, B.A.; Sawyer, H.; Scurlock, B.M.; Kauffman, M.J. Large herbivores surf waves of green-up in spring. Proc. R. Soc. B 2016, 283, 20160456. [CrossRef] [PubMed]

5. Lundberg, P. The evolution of partial migration in Birds. Trends Ecol. Evol. 1988, 3, 172-175. [CrossRef]

6. Newton, I.; Dale, L.C. Bird migration at different latitudes in eastern North America. Auk 1996, 113, 626-635. [CrossRef]

7. Newton, I.; Dale, L. Relationship between migration and latitude among west European birds. J. Anim. Ecol. 1996, 65, 137-146. [CrossRef]

8. Singh, N.J.; Börger, L.; Dettki, H.; Bunnefeld, N.; Ericsson, G. From migration to nomadism: Movement variability in a northern ungulate across its latitudinal range. Ecol. Appl. 2012, 22, 2007-2020. [CrossRef]

9. Berger, J. The last mile: How to sustain long-distance migration in mammals. Conserv. Biol. 2004, 18, 320-331. [CrossRef]

10. Bolger, D.T.; Newmark, W.D.; Morrison, T.A.; Doak, D.F. The need for integrative approaches to understand and conserve migratory ungulates. Ecol. Lett. 2008, 11, 63-77. [CrossRef]

11. Harris, G.; Thirgood, S.; Hopcraft, J.G.C.; Cromsigt, J.P.G.M.; Berger, J. Global decline in aggregated migrations of large terrestrial mammals. Endanger. Species Res. 2009, 7, 55-76. [CrossRef]

12. Hebblewhite, M.; Merrill, E.H. Demographic balancing of migrant and resident elk in a partially migratory population through forage-predation tradeoffs. Oikos 2011, 120, 1860-1870. [CrossRef]

13. Middleton, A.D.; Kauffman, M.J.; Mcwhirter, D.E.; Cook, J.G.; Cook, R.C.; Nelson, A.A.; Jimenez, M.D.; Klaver, R.W. Animal migration amid shifting patterns of phenology and predation: Lessons from a Yellowstone elk herd. Ecology 2013, 94, 1245-1256. [CrossRef] [PubMed] 
14. Middleton, A.D.; Merkle, J.A.; Mcwhirter, D.E.; Cook, J.G.; Cook, R.C.; White, P.J.; Kauffman, M.J. Green-wave surfing increases fat gain in a migratory ungulate. Oikos 2018, 127, 1060-1068. [CrossRef]

15. Farnsworth, M.L.; Wolfe, L.L.; Hobbs, N.T.; Burnham, K.P.; Williams, E.S.; Theobald, D.M.; Conner, M.M.; Miller, M.W. Human land use influences chronic wasting disease prevalence in mule deer. Ecol. Appl. 2005, 15, 119-126. [CrossRef]

16. Jesmer, B.R.; Goheen, J.R.; Aikens, E.O.; Merkle, J.A.; Monteith, K.L.; Beck, J.L.; Courtemanch, A.B.; McWhirter, D.E.; Hurley, M.A.; Miyasaki, H.M.; et al. Is ungulate migration culturally transmitted? Evidence of social learning from translocated animals. Science 2018, 361, 1023-1025. [CrossRef] [PubMed]

17. Caro, T.; Sherman, P.W. Vanishing behaviors. Conserv. Lett. 2012, 5, 159-166. [CrossRef]

18. Caro, T. Behavior and conservation: A bridge too far? Trends Ecol. Evol. 2007, 22, 394-400. [CrossRef]

19. Brown, D.G.; Johnson, K.M.; Loveland, T.R.; Theobald, D.M. Rural land-use trends in the conterminous United States, 1950-2000. Ecol. Appl. 2005, 15, 1851-1863. [CrossRef]

20. Sawyer, H.; Kauffman, M.J.; Nielson, R.M. Influence of well pad activity on winter habitat selection patterns of mule deer. J. Wildl. Manag. 2009, 73, 1052-1061. [CrossRef]

21. Wyckoff, T.B.; Sawyer, H.; Albeke, S.E.; Garman, S.L.; Kauffman, M.J. Evaluating the influence of energy and residential development on the migratory behavior of mule deer. Ecosphere 2018, 9, e02113. [CrossRef]

22. Fryxell, J.M.; Sinclair, A.R.E. Causes and consequences of migration by large herbivores. Trends Ecol. Evol. 1988, 3, 237-241. [CrossRef]

23. Utah Division of Wildlife Resources Utah Statewide Management Plan for Mule Deer; Utah Division of Wildlife Resources: Salt Lake City, UT, USA, 2014.

24. Department of the Interior Order No. 3362: Improving Habitat Quality in Western Big-Game Winter Range and Migration Corridors; United States Department of Interior: Washington, DC, USA, 2018.

25. Colwell, R.K.; Rangel, T.F. Hutchinson's duality: The once and future niche. Proc. Natl. Acad. Sci. USA 2009, 106, 19651-19658. [CrossRef] [PubMed]

26. Hutchinson, G.E. Concluding Remarks. Cold Spring Harb. Symp. Quant. Biol. 1957, 22, 415-427. [CrossRef]

27. Sawyer, H.; Merkle, J.A.; Middleton, A.D.; Dwinnell, S.P.H.; Monteith, K.L. Migratory plasticity is not ubiquitous among large herbivores. J. Anim. Ecol. 2019, 88, 450-460. [CrossRef] [PubMed]

28. Stoner, D.C.; Sexton, J.O.; Nagol, J.; Bernales, H.H.; Edwards, T.C. Ungulate reproductive parameters track satellite observations of plant phenology across latitude and climatological regimes. PLoS ONE 2016, 11, e0148780. [CrossRef] [PubMed]

29. Stoner, D.C.; Sexton, J.O.; Choate, D.M.; Nagol, J.; Bernales, H.H.; Sims, S.A.; Ironside, K.E.; Longshore, K.M.; Edwards, T.C. Climatically driven changes in primary production propagate through trophic levels. Glob. Chang. Biol. 2018, 24, 4453-4463. [CrossRef]

30. Jarvis, A.; Reuter, H.I.; Nelson, A.; Guevara, E. Hole-Filled SRTM for the Globe Version 4. CGIAR-CSI SRTM $90 \mathrm{~m}$ Database. 2008. Available online: http://srtm.csi.cgiar.org (accessed on 21 August 2019).

31. Banner, R.E.; Baldwin, B.D.; McGinty, E.L. Rangeland Resources of Utah; Utah State University: Logan, UT, USA, 2009.

32. Bradley, B.A.; Mustard, J.F. Comparison of phenology trends by land cover class: A case study in the Great Basin, USA. Glob. Chang. Biol. 2008, 14, 334-346. [CrossRef]

33. Travis, W.R. New Geographies of the American West: Land Use and the Changing Patterns of Place; Island Press: Washington, DC, USA, 2007.

34. Olson, D.D. Assessing Vehicle-Related Mortality of Mule Deer in Utah. Ph.D. Thesis, Utah State University, Logan, UT, USA, 2013.

35. Papworth, S.K.; Bunnefeld, N.; Slocombe, K.; Milner-Gulland, E.J. Movement ecology of human resource users: Using net squared displacement, biased random bridges and resource utilization functions to quantify hunter and gatherer behaviour. Methods Ecol. Evol. 2012, 3, 584-594. [CrossRef]

36. Rouse, J.W.; Hass, R.H.; Schell, J.A.; Deering, D.W. Monitoring vegetation systems in the great plains with ERTS. In Third Earth Resources Technology Satellite-1 Symposium-Volume I: Technical Presentations; NASA: Washington, DC, USA, 1974; Volume 1, pp. 309-317.

37. Tucker, C. Red and photographic infrared linear combinations for monitoring vegetation. Remote Sens. Environ. 1979, 8, 127-150. [CrossRef]

38. Didan, K. MOIDS/Terra Vegetation Indices 16-Day L3 Global 250 m SIN Grid V006. 2015. Available online: https://pdaac.usgs.gov/products/mod13q1v006/ (accessed on 21 August 2019). 
39. Pettorelli, N.; Ryan, S.; Mueller, T.; Bunnefeld, N.; Jedrzejewska, B.; Lima, M.; Kausrud, K. The Normalized Difference Vegetation Index (NDVI): Unforeseen successes in animal ecology. Clim. Res. 2011, 46, 15-27. [CrossRef]

40. Nolin, A.W. Recent advances in remote sensing of seasonal snow. J. Glaciol. 2011, 56, 1141-1150. [CrossRef]

41. Hall, D.K.; Riggs, G.A. MODIS/Terra Snow Cover Daily L3 Global 500 m GRID, Version 6. 2016. Available online: https://nsidc.org/data/mod10a1 (accessed on 21 August 2019).

42. Monteith, K.L.; Bleich, V.C.; Stephenson, T.R.; Pierce, B.M.; Conner, M.M.; Kie, J.G.; Bowyer, R.T. Life-history characteristics of mule deer: Effects of nutrition in a variable environment. Wildl. Monogr. 2014, 186, 1-62. [CrossRef]

43. Nicholson, M.C.; Bowyer, R.T.; Kie, J.G. Habitat selection and survival of mule deer: Tradeoffs associated with migration. J. Mammal. 1997, 78, 483-504. [CrossRef]

44. Rivrud, I.M.; Loe, L.E.; Mysterud, A. How does local weather predict red deer home range size at different temporal scales? J. Anim. Ecol. 2010, 79, 1280-1295. [CrossRef]

45. Sawyer, H.; Kauffman, M.J. Stopover ecology of a migratory ungulate. J. Anim. Ecol. 2011, 80, $1078-1087$. [CrossRef] [PubMed]

46. Homer, C.; Dewitz, J.; Yang, L.; Jin, S.; Danielson, P.; Xian, G.; Coulston, J.; Herold, N.; Wickham, J.; Megown, K. Completion of the 2011 National Land Cover Database for the conterminous United States-representing a decade of land cover change information. Photogramm. Eng. Remote Sens. 2015, 81, 345-354.

47. Breiman, L. Random forests. Mach. Learn. 2001, 45, 5-32. [CrossRef]

48. Cutler, D.R.; Edwards, T.C.; Beard, K.H.; Cutler, A.; Hess, K.T.; Gibson, J.; Lawler, J.J. Random Forests for Classification in Ecology. Ecology 2007, 88, 2783-2792. [CrossRef]

49. Strobl, C.; Boulesteix, A.L.; Kneib, T.; Augustin, T.; Zeileis, A. Conditional variable importance for random forests. BMC Bioinform. 2008, 9, 307. [CrossRef]

50. Utah Division of Wildlife Resources Habitat Coverages: Mule Deer Habitat. 2015. Available online: https://dwrcdc.nr.utah.gov/ucdc/ (accessed on 21 August 2019).

51. R Core Team. R: A Language and Environment for Statistical Computing; R Core Team: Vienna, Austria, 2016.

52. Liaw, A.; Wiener, M. Classification and Regression by randomForest. $R$ News 2002, 2, 18-22.

53. Sawyer, H.; Lindzey, F.; McWhirter, D. Mule deer and pronghorn migration in western Wyoming. Wildl. Soc. Bull. 2005, 33, 1266-1273. [CrossRef]

54. Barker, K.J.; Mitchell, M.S.; Proffitt, K.M.; DeVoe, J.D. Land management alters traditional nutritional benefits of migration for elk. J. Wildl. Manag. 2019, 83, 167-174. [CrossRef]

55. Vogel, W.O. Response of deer to density and distribution of housing in Montana. Wildl. Soc. Bull. 1989, 17, 406-413.

56. Anderson, E.D.; Long, R.A.; Atwood, M.P.; Kie, J.G.; Thomas, T.R.; Zager, P.; Bowyer, R.T. Winter resource selection by female mule deer Odocoileus hemionus: Functional response to spatio-temporal changes in habitat. Wildl. Biol. 2012, 18, 153-163. [CrossRef]

57. Tucker, M.A.; Böhning-gaese, K.; Fagan, W.F.; Fryxell, J.M.; Van Moorter, B.; Alberts, S.C.; Ali, A.H.; Allen, A.M.; Attias, N.; Avgar, T.; et al. Moving in the Anthropocene: Global reductions in terrestrial mammalian movements. Science 2018, 359, 466-469. [CrossRef] [PubMed]

58. Bracis, C.; Mueller, T. Memory, not just perception, plays an important role in terrestrial mammalian migration. Proc. R. Soc. B Biol. Sci. 2017, 284. [CrossRef] [PubMed]

59. Garrott, R.A.; White, G.C.; Bartmann, R.M.; Carpenter, L.H.; Alldredge, A.W. Movements of female mule deer in northwest Colorado. J. Wildl. Manag. 1987, 51, 634-643. [CrossRef]

60. Aikens, E.O.; Kauffman, M.J.; Merkle, J.A.; Dwinnell, S.P.H.; Fralick, G.L.; Monteith, K.L. The greenscape shapes surfing of resource waves in a large migratory herbivore. Ecol. Lett. 2017, 20, 741-750. [CrossRef]

61. Fensholt, R.; Sandholt, I.; Rasmussen, M.S. Evaluation of MODIS LAI, fAPAR and the relation between fAPAR and NDVI in a semi-arid environment using in situ measurements. Remote Sens. Environ. 2004, 91, 490-507. [CrossRef]

62. Mueller, T.; Fagan, W.F. Search and navigation in dynamic environments-From individual behaviours to population distributions. Oikos 2008, 117, 654-664. [CrossRef]

(C) 2019 by the authors. Licensee MDPI, Basel, Switzerland. This article is an open access article distributed under the terms and conditions of the Creative Commons Attribution (CC BY) license (http://creativecommons.org/licenses/by/4.0/). 